\title{
Passive leg-lifting in heart failure patients predicts exercise-induced rise in left ventricular filling pressures
}

\author{
E. Tossavainen ${ }^{1} \cdot$ G. Wikström ${ }^{2} \cdot$ M. Y. Henein ${ }^{1} \cdot$ M. Lundqvist ${ }^{2} \cdot$ U. Wiklund $^{3} \cdot$ P. Lindqvist ${ }^{4}$ (D)
}

Received: 22 March 2019 / Accepted: 18 July 2019 / Published online: 31 July 2019

(c) The Author(s) 2019

\begin{abstract}
Aim The aim of this study was to assess PCWP with passive leg-lifting (PLL) and exercise, in two groups of patients presenting with normal left ventricular ejection fraction (LVEF); one group with elevated NT-proBNP (eBNP), and one with normal NT-proBNP (nBNP) plasma concentration.

Methods and results Fifty-one patients with eBNP (NT-proBNP $\geq 125 \mathrm{ng} / \mathrm{l}$ ) and LVEF $>50 \%$, were investigated and compared with 34 patients with nBNP (NT-proBNP $<125 \mathrm{ng} / \mathrm{l}$ ) and LVEF $>50 \%$. Both groups underwent right heart catheterization (RHC) at rest, PLL and exercise. From RHC, mean pulmonary arterial pressure (mPAP), cardiac output (CO), and PCWP were measured. All nBNP patients had PCWP $<15 \mathrm{mmHg}$ at rest, and a PCWP of $<25 \mathrm{mmHg}$ with PLL and during exercise. Patients with eBNP had higher $(p<0.01)$ resting mPAP, PCWP, and mPAP/CO. These values increased with exercise; however, $\mathrm{CO}$ increased less in comparison with nBNP patients $(p=0.001)$. 20\% of patients with eBNP had a PCWP $>15 \mathrm{mmHg}$ at rest, this percentage increased to $47 \%$ with PLL and $41 \%$ had a PCWP $>25 \mathrm{mmHg}$ during exercise. Of those with PCWP $>25 \mathrm{mmHg}$ during exercise, $91 \%$ had a PCWP $>15 \mathrm{mmHg}$ with PLL. A PCWP $>15 \mathrm{mmHg}$ on PLL had a $91 \%$ sensitivity and $92 \%$ specificity in predicting exercise-induced PCWP of $>25 \mathrm{mmHg}$.

Conclusion In patients presenting with eBNP, PLL can predict which patients will develop elevated PCWP with exercise. These findings highlight the role of stress assessment.
\end{abstract}

Electronic supplementary material The online version of this article (https://doi.org/10.1007/s00392-019-01531-w) contains supplementary material, which is available to authorized users.

E. Tossavainen

Erik.tossavainen@vll.se

1 Department of Public Health and Clinical Medicine, Cardiology, Umeå University, S-90185 Umeå, Sweden

2 Department of Medical Sciences,Cardiology, Uppsala University, Uppsala, Sweden

3 Department of Radiation Sciences, Biomedical Engineering, Umeå University, Umeå, Sweden

4 Department of Surgical and Perioperative Sciences, Clinical Physiology, Umeå University, Umeå, Sweden 


\section{Graphic abstract}

Rest

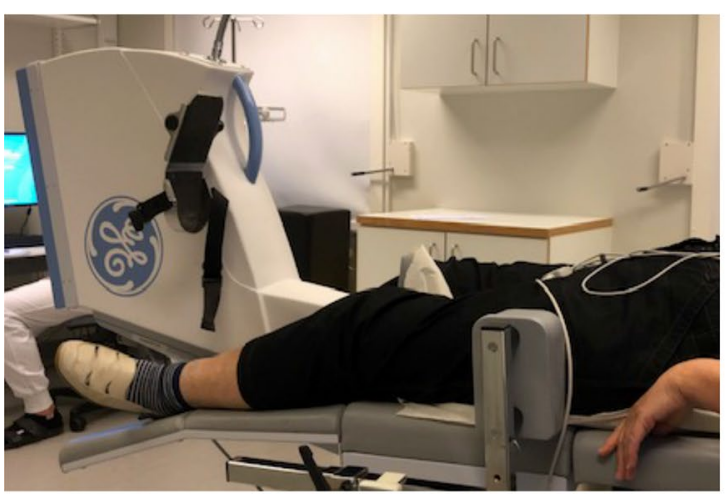

\section{Exercise}
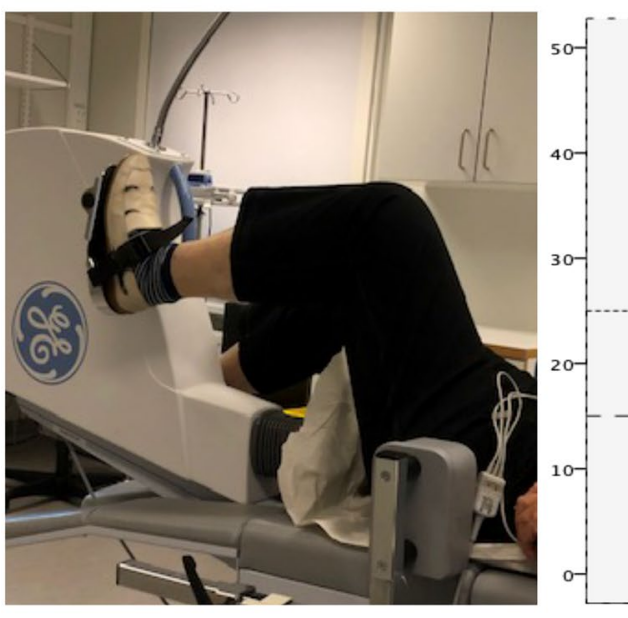

Passive leg lifting (PLL)
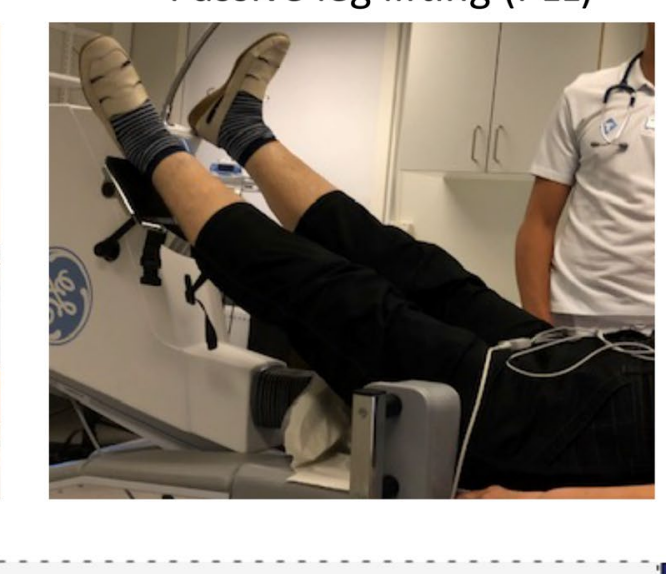

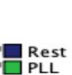

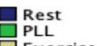

Exercise

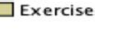


for suspected HF. From this database, 153 patients were identified, 51 of those (mean age $65 \pm 10$ years, 24 females) had LVEF $>50 \%$ and NT-proBNP $>125 \mathrm{ng} / \mathrm{ml}$ : these patients were classified as eBNP. In addition, 34 patients (mean age $50 \pm 14$ years, 18 females) with $\mathrm{LVEF}>50 \%$ and NT-proBNP $\leq 125 \mathrm{ng} / \mathrm{ml}$, were used as a comparison and defined as nBNP patients. 57 patients with LVEF $<50 \%$, and 11 patients who fulfilled PAH criteria were excluded. This study complied with the Declaration of Helsinki and was approved by the Ethical approval board in Uppsala.

\section{Right heart catheterisation (RHC)}

Venous access was established by inserting a cannula in the right internal jugular vein, a median cubital vein or in the right femoral vein. In a few patients, access was not possible from the jugular vein, and those patients were catheterised from the femoral vein. A small introducer $(5 \mathrm{~F})$ was used and no complications were observed in patients performing PLL and supine bicycle exercise.

A retrograde catheterisation was then performed using a Swan-Ganz® Standard Thermodilution Catheter (Edwards Lifesciences) [12]. Mean right atrial pressure (RAP), systolic and end-diastolic right ventricular pressures, pulmonary artery systolic, mean and diastolic pressures (PASP, PAMP, and PADP, respectively), and PCWP were all measured according to standard guidelines [13]. PCWP was measured by averaging ten consecutive pressure curve tracings.

Blood samples for estimation of oxygen saturation were drawn from the superior cava (SVC), PA and femoral artery; $8 \%$ was considered as significant oxygen saturation differential between the SVC and the pulmonary artery and thus considered to indicate a shunt. Cardiac output (CO) was determined by thermodilution [14]. Pulmonary vascular resistance (PVR) was calculated using the equation PAMP-PCWP (trans-pulmonary gradient) divided by CO. After acquiring a complete baseline RHC examination the PLL test was performed. The patient's legs were passively lifted and rested on the bicycle pedals for up to $3 \mathrm{~min}$ before the start of exercise. Supine submaximal exercise testing was performed by a 6-min steady state supine bicycle exercise test with load level of 20-70 Watts depending on patient's tolerability. PA-pressures, stroke volume and PCWP as well as calculated trans-pulmonary gradient (TPG), PVR and CO were measured at rest and again at peak exercise. PA-pressures and PCWP were also measured during PLL, and TPG was calculated.

\section{Statistical analysis}

The statistical software package IBM SPSS Statistics, version 24 (IBM Corp. Armonk, NY, USA) and MATLAB
(Mathworks Inc, Natick, MN, USA) were used for all calculations and graphic presentations. Patient characteristics were expressed as median \pm inter quartile range (IQR). Group comparisons were performed using Mann-Whitney $U$-test, Cochran-Mantel-Haenszel test and Fisher's exact probability or $X^{2}$ test. Wilcoxon signed-ranks test was utilized to identify significant differences at different conditions. Two-way analysis of variance (ANOVA) was used to compare exercise data (mPAP/CO at exercise and the change from rest) from different groups, categorized into three groups after NT-proBNP and PCWP, as well as in two groups after PVR, with paired $t$ tests as post-hoc tests. Sensitivity and specificity were calculated to predict elevated PCWP from resting NT-proBNP. Pearson correlation analysis was performed to evaluate relationship between NTproBNP and mPAP and PCWP at rest, passive leg-lifting and exercise. A $p$ value $<0.05$ was determined as statistically significant.

\section{Results}

Baseline characteristics are shown in Table 1.

None of the patients with normal NT-proBNP had mPAP $>25 \mathrm{mmHg}$ at rest, whereas one had mPAP $>30 \mathrm{mmHg}$ with PLL and 8 had $\mathrm{mPAP}>30 \mathrm{mmHg}$ during exercise (Fig. 1). Also, none of the patients with normal NT-proBNP had PCWP $>15 \mathrm{mmHg}$ at rest or with PLL, and none had PCWP $>25 \mathrm{mmHg}$ during exercise (Fig. 2). In the same group, mPAP and PCWP increased with PLL ( $p<0.001$ for both), as did mPAP, PCWP, TPG and $\mathrm{CO}(p<0.001$ for all), whereas mPAP/CO slightly decreased with exercise (Table 2).

In patients with elevated NT-proBNP, mPAP $(p<0.001), \mathrm{PCWP} / \mathrm{CO}(p=0.03), \mathrm{mPAP} / \mathrm{CO}(p=0.002)$, PCWP $(p=0.006)$, PVR $(p=0.007)$, and TPG $(p=0.001)$ were all already higher than in those with normal NTproBNP at rest. CO did not differ from patients with normal NT-proBNP at rest. In the eBNP group, mPAP $(p<0.001)$, PCWP $(p<0.001)$ and TPG $(p<0.05)$ increased with PLL. Similarly, mPAP, PCWP, and TPG $(p<0.001)$ as well as $\mathrm{CO}(p<0.001)$ all increased with exercise in comparison to rest. PVR did not significantly change in any of the groups, however, $\mathrm{mPAP} / \mathrm{CO}$ and $\mathrm{PCWP} / \mathrm{CO}$ increased $(p<0.001)$ in subjects with eBNP, whereas nBNP was associated with decreased or unchanged ratios $(p<0.05)$ (Table 2). mPAP at rest, with PLL and during exercise are shown in Fig. 1. Only $20 \%$ of patients with elevated NT-proBNP had a PCWP $>15 \mathrm{mmHg}$ at rest, this percentage increased to $47 \%$ with PLL and $41 \%$ had a PCWP $>25 \mathrm{mmHg}$ during exercise. Out of those with elevated NT-proBNP and PCWP $>25 \mathrm{mmHg}$ during exercise, $91 \%$ had PCWP $>15 \mathrm{mmHg}$ with PLL (Fig. 2). The 
Table 1 Baseline characteristics for groups classified according to normal (nBNP) or elevated (eBNP) NT-proBNP

\begin{tabular}{lllc}
\hline & nBNP(34) & eBNP (51) & p-Value \\
\hline Resting data & & & \\
Age, years & $51(35-63)$ & $67(60-71)$ & $<0.001$ \\
Female & 18 & 24 & 0.60 \\
ACE inhibitors & 13 & 36 & 0.004 \\
Betablockers & 7 & 30 & 0.001 \\
Diuretics & 3 & 21 & 0.003 \\
Calcium channel blockers & 7 & 14 & 0.47 \\
Atrial fibrillation or flutter & 2 & 17 & 0.008 \\
IHD & 1 & 9 & 0.07 \\
SHT & 11 & 26 & 0.06 \\
DM & 1 & 8 & 0.09 \\
NT-pro BNP, ng/L & $54(33-73)$ & $440(178-1402)$ & $<0.001$ \\
Creatinine, micro mol/L & $73(61-86)$ & $84(68-111)$ & 0.015 \\
GFR, ml/min & $95(61-86)$ & $58(43-76)$ & $<0.001$ \\
Systolic blood pressure, mmHg & $126(119-140)$ & $130(120-150)$ & $<0.045$ \\
Workload, Watt & $50(50-75)$ & $43(39-50)$ & $<0.001$ \\
Heart rate, rest, bpm & $66(59-80)$ & $71(58-76)$ & 0.716 \\
Height, cm & $174(167-179)$ & $174(165-180)$ & 0.757 \\
Weight, kg & $79(71-87)$ & $84(75-92)$ & 0.125 \\
\hline
\end{tabular}

Mann-Whitney and Cochran-Mantel-Haenszel tests were used in the analysis of background characteristics. Out of the 21 eBNP-patients with diuretics, one received Thiazide treatment instead of loop diuretics and one was treated with both Thiazide and Loop diuretics

$I H D$ ischemic heart disease, $S H T$ systemic hypertension, $D M$ diabetes mellitus, $B N P$ brain natriuretic peptides, GFR glomerular filtration rate
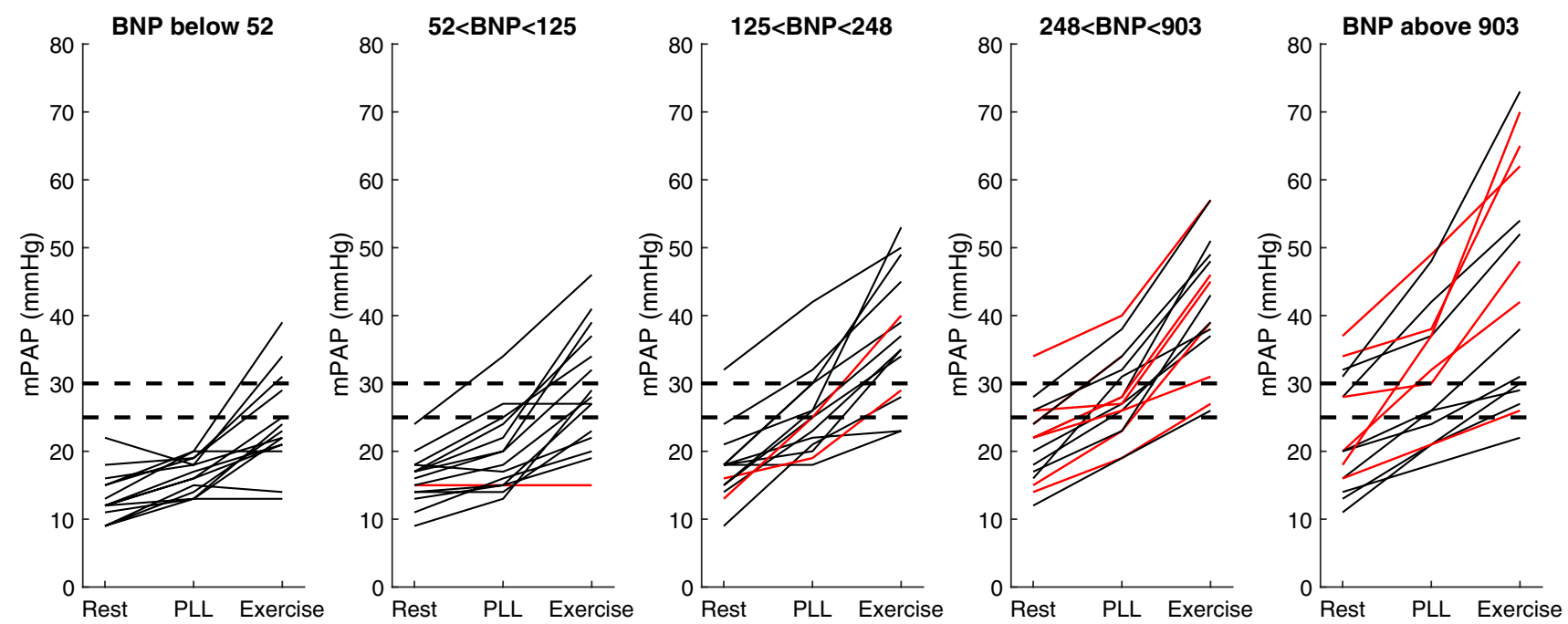

Fig. $1 \mathrm{mPAP}$ at rest, passive leg-lifting $(P L L)$ and where patients are divided in quantiles based on NT-proBNP. Red lines show patients with atrial fibrillation $(A F)$. Dotted lines represent 25 and $30 \mathrm{mmHg}$ as cutoff values for normal values at rest and exercise

sensitivity and specificity of PCWP $>15 \mathrm{mmHg}$ with PLL in predicting PCWP of $>25 \mathrm{mmHg}$ during exercise were $91 \%$ and $92 \%$, respectively. The basic characteristics and hemodynamics in patients with: (1) normal PCWP at rest and exercise; (2) normal PCWP at rest but elevated during exercise; and (3) increased PCWP at both rest and exercise are shown in Supplementary Materials, Tables 3 and 4.

In addition to significant PCWP changes during PLL and exercise, mPAP/CO and PCWP/CO both increased significantly in eBNP patients who developed high filling 

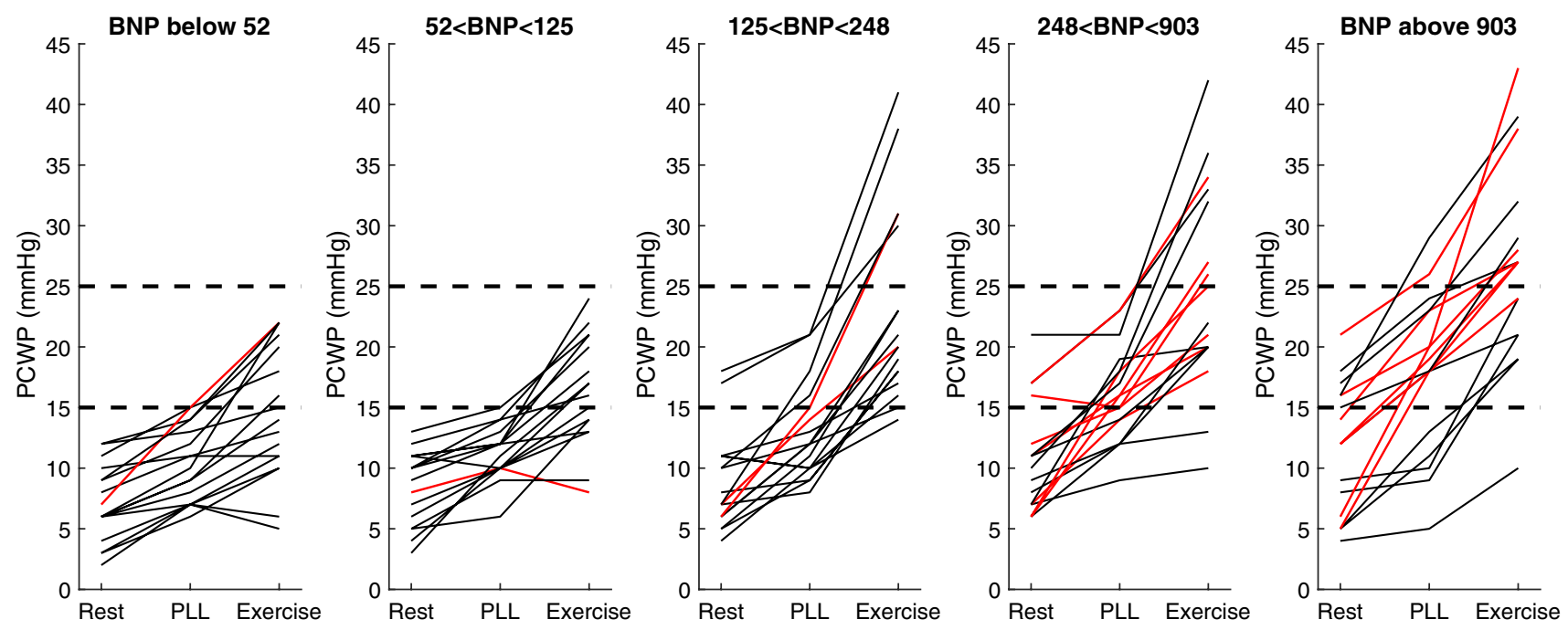

Fig. 2 PCWP at rest, passive leg-lifting ( $P L L)$ and where patients are divided in quantiles based on NT-proBNP. Red lines show patients with atrial fibrillation $(A F)$. Dotted lines represent 15 and $25 \mathrm{mmHg}$ as cutoff values at rest and exercise

Table 2 Groups classified according to normal or elevated NTproBNP

\begin{tabular}{lccr}
\hline & nBNP(34) & eBNP $(51)$ & $p$ value \\
\hline Resting data RHC & & & \\
mPAP, mmHg & $14.5(12-17)$ & $18(15-24)$ & $<0.001$ \\
CO, 1/min & $5.4(4.7-6.0)$ & $5.8(4.6-7.2)$ & 0.72 \\
PCWP/CO, & $1.4(1.0-1.8)$ & $1.7(1.0-2.4)$ & 0.09 \\
mmHg/l/min & & & \\
mPAP/CO, & $2.5(2.2-3.3)$ & $3.3(2.6-4.3)$ & 0.003 \\
mmHg/l/min & & & \\
PCWP, mmHg & $8.0(5.8-10.3)$ & $10.0(6-14)$ & 0.03 \\
PVR, WU & $1.2(0.9-1.8)$ & $1.6(1.1-2.4)$ & 0.01 \\
TPG, mmHg & $6.5(5.0-9.3)$ & $10.0(7-12)$ & 0.001 \\
PLL data RHC & & & \\
mPAP, mmHG & $17.5(15-20)^{* *}$ & $26(22.5-33)^{* *}$ & $<0.001$ \\
PCWP, mmHg & $10.5(9-13)^{* *}$ & $15(12-19)^{* *}$ & $<0.001$ \\
TPG, mmHg & $7(5-9)$ & $12(9.5-16)^{* *}$ & $<0.001$ \\
Exercise data RHC & & & \\
mPAP, mmHg & $26.5(21-34)^{* *}$ & $38.5(29-49)^{* *}$ & $<0.001$ \\
CO, l/min & $11.1(9.8-13.0)^{* *}$ & $9.6(8.7-11.2)^{* *}$ & 0.002 \\
PCWP/CO, & $1.4(0.9-1.8)$ & $2.4(1.8-3.4)^{* *}$ & $<0.001$ \\
mmHg/l/min & & & \\
mPAP/CO, Hg/ml/ & $2.2(1.8-3.1)^{*}$ & $3.9(3.2-5.5)^{* *}$ & $<0.001$ \\
min & & & \\
PCWP, mmHg & $15.0(11-20.3)^{* *}$ & $23(19-31)^{* *}$ & $<0.001$ \\
PVR, WU & $1.0(0.6-1.3)$ & $1.5(1.0-2.2)$ & 0.005 \\
TPG, mmHg & $11.5(7.0-15.3)^{* *}$ & $14(9-20)^{* *}$ & 0.10 \\
\hline
\end{tabular}

$P L L$ passive leg-lifting, $m P A P$ mean pulmonary artery pressures, $C O$ cardiac output, $P C W P$ pulmonary capillary wedge pressures, $P V R$ pulmonary vascular resistance, $T P G$ transpulmonary gradient

${ }^{*} p<0.05$ compared with rest, ${ }^{* *} p<0.001$ compared with rest. MannWhitney test was used in the analysis between groups and Wilcoxon signed-ranks test was utilized to identify significant differences at different conditions pressure during exercise, in contrast to a tendency towards a decrease, among nBNP patients (Table 2). The correlation between the two ratios was strong $\left(r^{2}=0.64\right)$. We found moderate correlations $\left(\mathrm{r}^{2}=0.15-0.33\right)$ between NT-proBNP and mPAP as well as PCWP in patients with normal and elevated NT-proBNP, with or without atrial fibrillations. (Fig. 3) Furthermore, we found a strong correlation $\left(\mathrm{r}^{2}=0.37-0.80\right)$ between $\mathrm{mPAP}$ at rest to $\mathrm{mPAP}$ at PLL and exercise as well as PCWP at rest and PCWP during PLL and exercise in patients with normal and elevated NT-proBNP, with or without atrial fibrillations. (Figs. 4, 5).

The ratio of $\mathrm{mPAP} / \mathrm{CO}$ was also found to be associated with pulmonary vascular remodeling (Fig. 6), where there were statistically significant differences in mPAP/CO when patients were categorized based on NT-proBNP, and PWCP (ANOVA, $p<0.001$ ), and PVR $>2$ WU was consistently associated with a higher ratio in all three groups based on NT-proBNP and PCWP (ANOVA, $p<0.001$ ). Post-hoc testing showed that mPAP/CO was significantly increased in eBNP patients who developed high filling pressure during exercise. Finally, the relationship to PVR was lost with the delta change in mPAP/CO (ANOVA, $p=0.83$ ), whereas the differences between different levels of delta mPAP/CO remained (ANOVA, $p<0.001$ ) (Supplememental files, Fig. 7). The sensitivity for NTproBNP $>125 \mathrm{ng} / \mathrm{l}$ in predicting elevated PCWP during rest, PLL or exercise were $100 \%$ for all. The specificity for NT-proBNP > $125 \mathrm{ng} / \mathrm{l}$ in predicting elevated PCWP during rest, PLL or exercise was $46 \%, 57 \%$, and $54 \%$, respectively. 

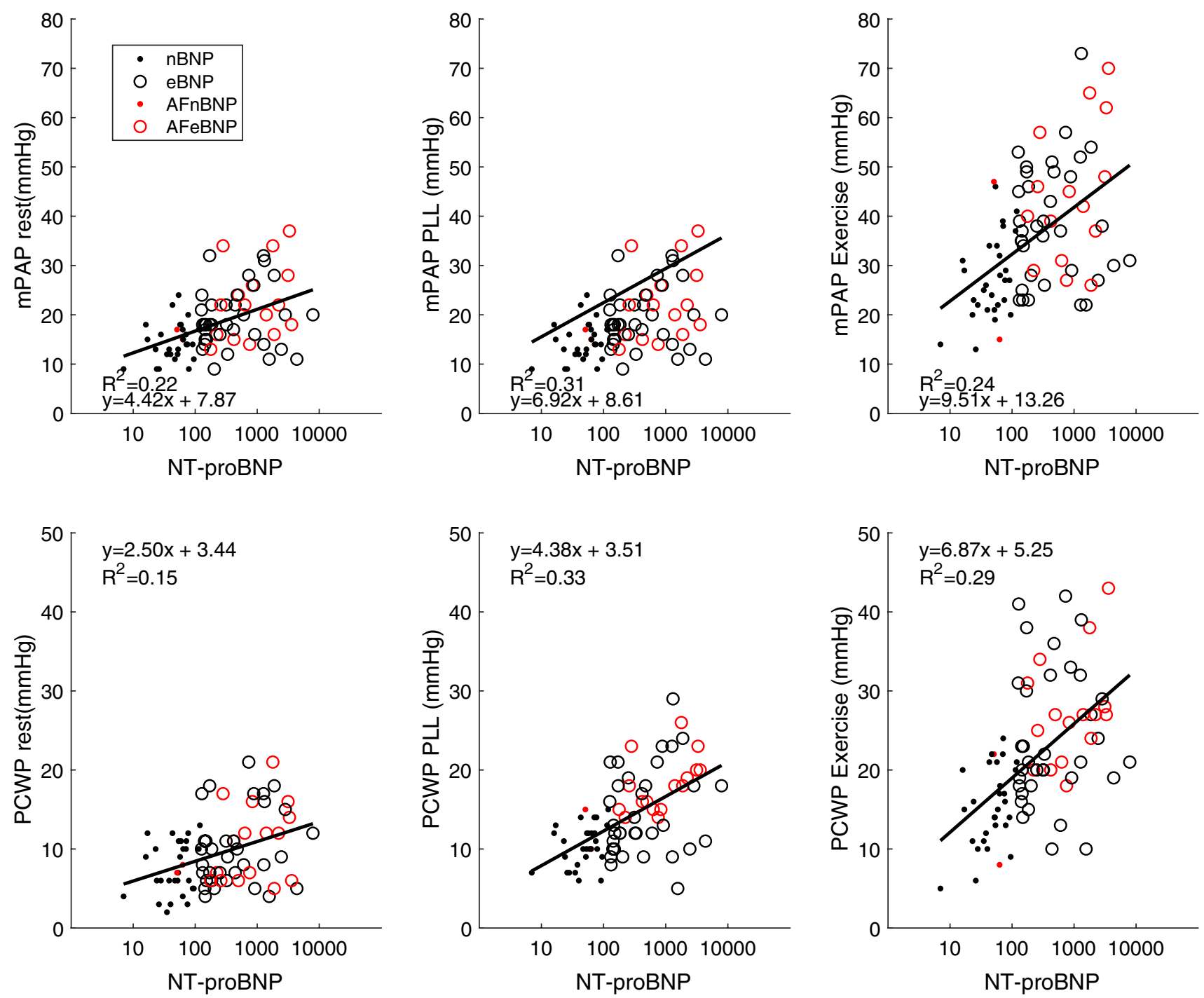

Fig. 3 Correlation between NT-proBNP and mPAP (top) and PCWP (bottom) at rest, passive leg-lifting (PLL) and exercise. $n B N P$ normal NTproBNP, $e B N P$ elevated NT-proBNP, $A F$ atrial fibrillation

\section{Discussion}

As a group, eBNP patients had relatively normal resting PCWP ( $80 \%$ of patients) at rest, which increased significantly with PLL, and further increased during exercise when compared to controls. In individual patients, only $20 \%$ had PCWP $>15 \mathrm{mmHg}$ at rest; however, this increased to $47 \%$ with PLL. $41 \%$ of patients had PCWP $>25 \mathrm{mmHg}$ during exercise, and $91 \%$ of them had PCWP $>15 \mathrm{mmHg}$ with PLL.

This resulted in a PCWP $>15 \mathrm{mmHg}$ with PLL $91 \%$ sensitive and $92 \%$ specific in predicting PCWP $>25 \mathrm{mmHg}$ during exercise. In addition, an increase in delta-mPAP/CO was associated with increase in PCWP, irrespectively of PVR. Finally, elevated NT-proBNP at rest was found to be a modestly accurate predictor of elevated PCWP with PLL and during supine bicycle exercise. However, NT-proBNP within normal ranges had a strongly negative predictive value for estimating PCWP during exercise, and is strongly suggestive of normal diastolic LV compliance.

This information might be of value in daily clinical practice improving assessment and interpretation of LVFPs. The exact use of NT-proBNP in HF patients, especially with LVEF $>50 \%$, is not well defined and varies in different studies $[15,16]$, however, it has been proven to be related to LVFPs and diastolic function, as well as having a good prognostic value [17].

\section{Data interpretation}

The most common pathology in HF patients, with normal or preserved LVEF is long-standing hypertension and its consequential effects on the LV, in the form of cavity stiffness 

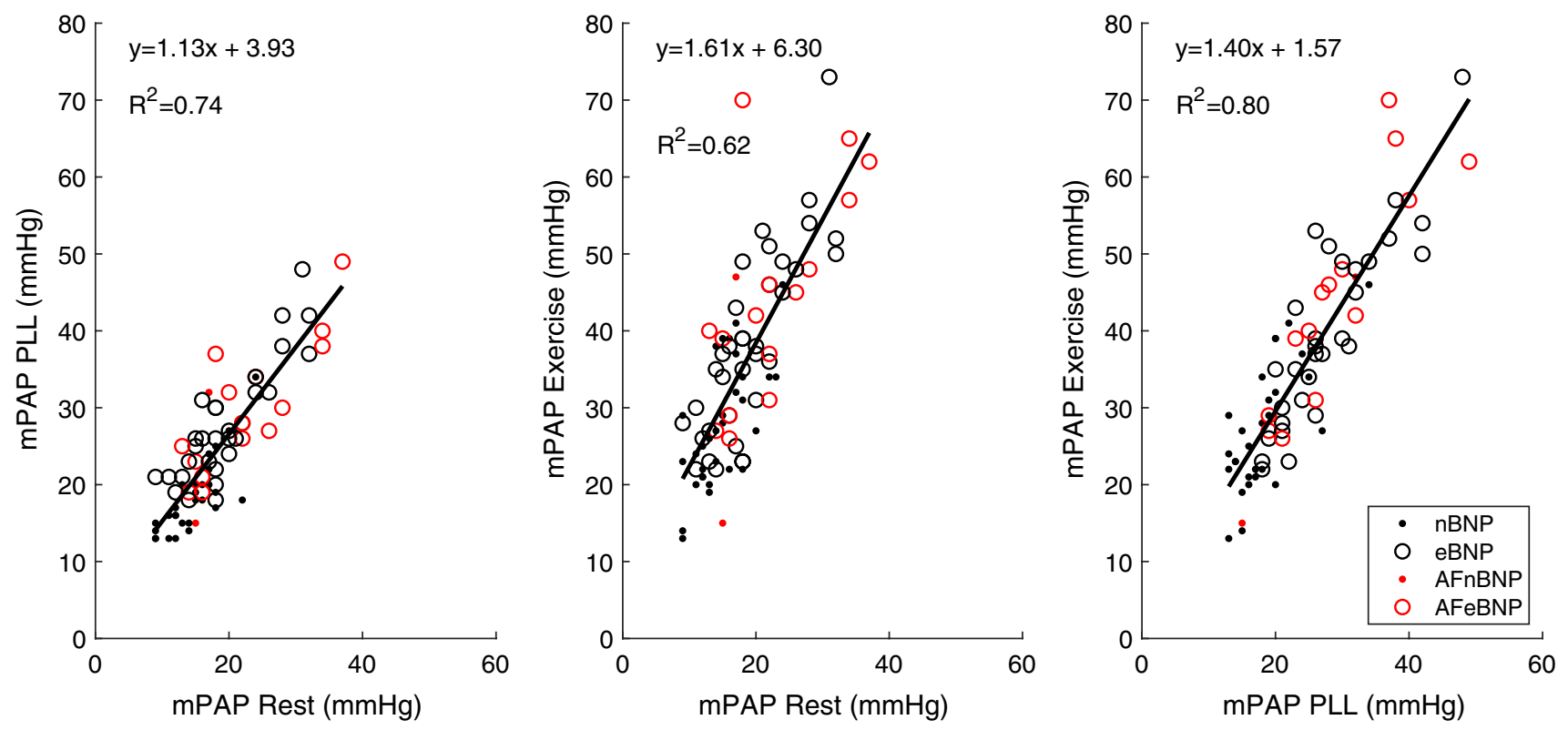

Fig. 4 Correlation between mPAP at rest, passive leg-lifting $(P L L)$ and exercise. $n B N P$ normal NT-proBNP, eBNP elevated NT-proBNP, $A F$ atrial fibrillation
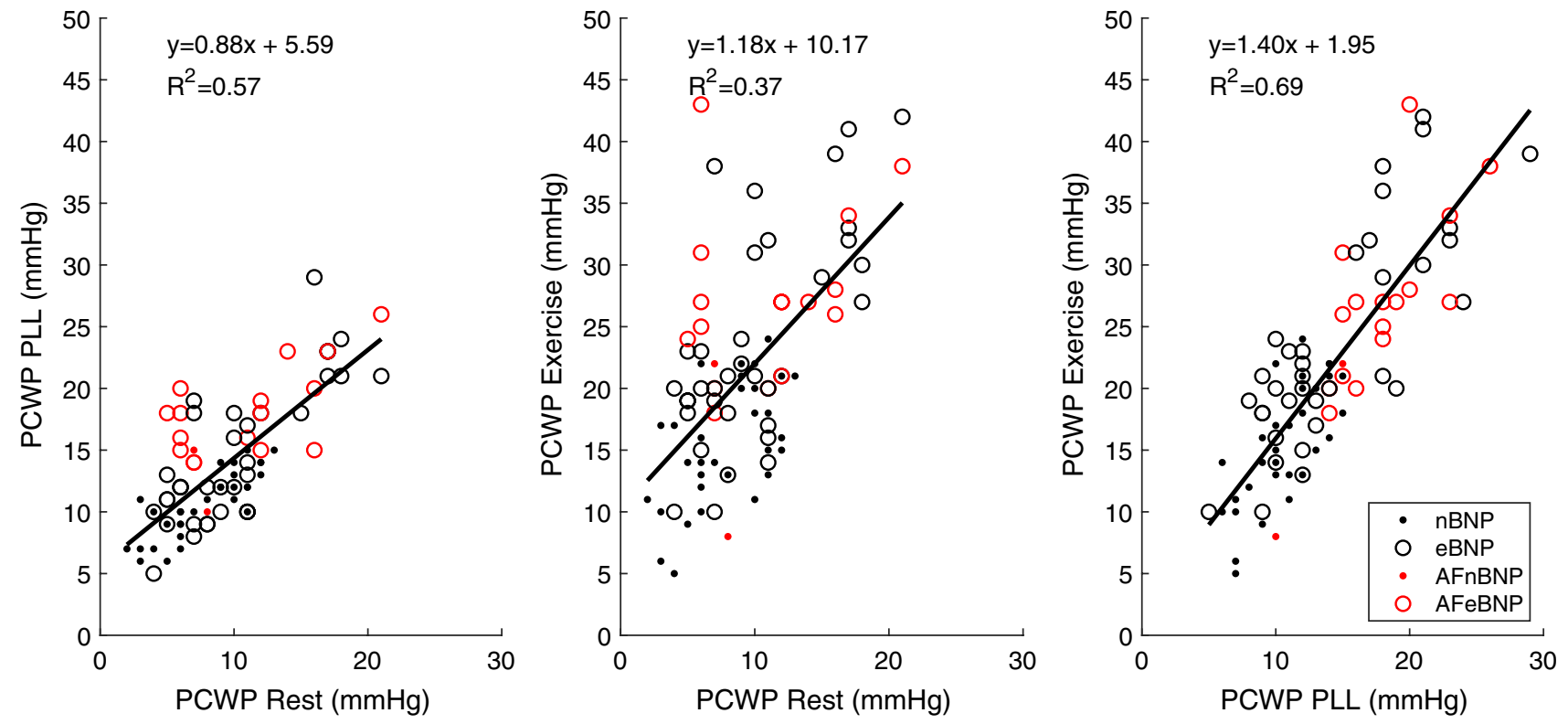

Fig. 5 Correlation between PCWP at rest, passive leg-lifting $(P L L)$ and exercise. $n B N P$ normal NT-proBNP, $e B N P$ elevated NT-proBNP, $A F$ atrial fibrillation

and raised filling pressures, reflected as a rise in PCWP. The majority of our eBNP patients who were limited by breathlessness did not have raised PCWP at rest; however, $41 \%$ of them developed abnormally raised PCWP $>25 \mathrm{mmHg}$ during moderate work load exercise. This finding supports the diagnosis of HF and also explains patient's symptoms. The mechanism behind normal filling pressures, despite a stiff myocardium and elevated BNP, may be due to at least two reasons. First, a large proportion of patients was already on diuretics treatment, and second, endogenous BNP secretion has a diuretic effect.

The important finding in our results was the patient response to PLL, during which a significant rise in PCWP $>15 \mathrm{mmHg}$, was seen in $47 \%$ of the patients, the 


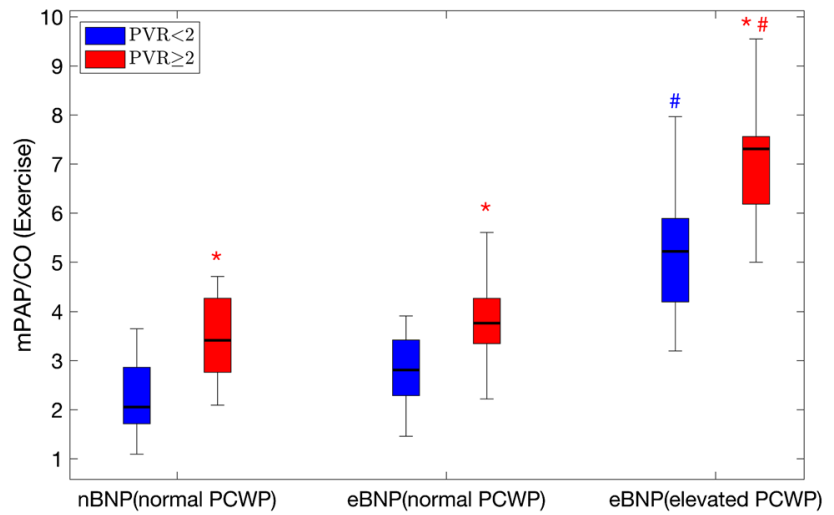

Fig. $6 \mathrm{mPAP} / \mathrm{CO}(\mathrm{mmHg} / \mathrm{L} / \mathrm{min})$ at exercise in $\mathrm{nBNP}$ (left), eBNP with normal PCWP at exercise (middle), and eBNP with elevated PCWP at exercise (right). Right red boxes are patients with $P V R \geq 2 W U$ and left blue PVR $<2$ WU. Note that both PVR and PCWP increased the mPAP/CO ratio. ${ }^{*} p<0.05$ between PVR groups, within the same BNP and PCWP groups. $\# p<0.05$ elevated PCWP vs normal PCWP, within the same PVR groups. Boxes show median and IQR, whiskers show range

majority of whom continued to experience rising PCWP, above $>25 \mathrm{mmHg}$, during exercise. Well-defined cutoff values for PCWP during PPL and exercise are not well established. However, according to recent guidelines [18] PCWP $>15 \mathrm{mmHg}$ at rest is recommended as a marker for raised resting LVFPs. Furthermore, with PLL and submaximal exercise, the majority of patients with normal NTproBNP did not exceed PCWP of $15 \mathrm{mmHg}$ and $25 \mathrm{mmHg}$, respectively [19]. In addition, the close relationship between the values obtained during PPL and exercise, illustrates the significant accuracy of the PLL maneuvers ability to predict hemodynamics outcomes and effects during exercise. A number of explanations for this relationship need to be discussed, in particular the effect of venous return and ventricular-arterial coupling, commonly known to be disturbed in $\operatorname{HF}[20,21]$.

With PLL, and during exercise, the venous return to the heart increases, which, in the presence of a stiff LV cavity, is coupled to an increase in LA pressures hence a subsequent rise in PCWP [8, 22-24]. However, exercise also influences afterload. Significant hemodynamic differences among patients with or without elevated NT-proBNP become evident when challenged, even though NT-proBNP levels are raised within the entire eBNP group. It has been reported that patients with elevated NT-proBNP levels and normal hemodynamic response may be attributed to the protective properties of increased BNP levels. However, in our patients we found resting NT-proBNP to be accurate in identifying abnormal PCWP increase, both during PLL and exercise.

The RV afterload is the total pulmonary vascular resistance (TPVR), constituted by the sum of the transpulmonary gradient and PCWP, divided by CO. An increased TPVR, regardless of resting or stress conditions, suggests underlying disease within the pulmonary vascular or post capillary system, with an exercise mPAP/CO ratio of $>3 \mathrm{WU}$ predicting exercise pulmonary hypertension [25, 26]. Current definition [27] of exercise pulmonary hypertension also includes exercise-mPAP $>30 \mathrm{mmHg}$ criterion.

Since PVR is fixed, or decreases during exercise, rapidly elevated left-sided filling pressures should be considered if mPAP/CO increases during stress. Using the mPAP/CO changes during exercise in our analysis showed that PVR did not have any potential influence on the pressure and flow alterations found in this study, thus leaving increased left ventricular FPs as the main explanation of mPAP/CO increase. Recently [24] PCWP/CO during exercise has been found to predict exercise capacity and HF outcome; however, it is known to be accurately assessed by echocardiography.

In this study, other factors, i.e., age and atrial fibrillation were robust measures highly indicative of elevated LVFPs during exercise, as well as weight in indicating raised high PCWP at rest. An important finding in our study is that the use of PLL and/or supine bicycling in patients with NTproBNP of $125 \mathrm{ng} / \mathrm{l}$ or more, better stratifies patients, while NT-proBNP $<125 \mathrm{ng} / \mathrm{l}$ remains a robust marker of normal PCWP, therefore, making heart failure highly unlikely. This is in accordance with previous trials of HFpEF which consistently show that NT-proBNP is the most powerful prognostic marker [17].

\section{Clinical implications}

In patients with eBNP, resting RHC measurements showing normal PCWP should not be taken as a complete comprehensive examination, and consequently the same limitation applies for echocardiography. In case of normal findings at rest, some sort of stress test has to be undertaken to grade $\operatorname{HF}[15,28,29]$. Our findings support the current guidelines which highlight the important use of stress echocardiography in the routine management of HF patients [30, 31]. They propose PLL as a complementary simple investigation, which could be used in all patients with exertional dyspnea, as means for assessing LVFPs using echocardiography, in an outpatient setting. The use of echocardiography in PLL remains to be tested and the most accurate markers of PCWP identified before it becomes clinically applicable. The changes in mPAP/CO in HF patients might also be of specific interest as it can be assessed by noninvasive Doppler echocardiography.

\section{Limitations}

This is a retrospective, non-randomised, single-center study. Both patient groups were taking medications, but more commonly in the patient group with elevated NT-proBNP, which 
could influence the measurements. The nBNP patients were younger than eBNP patients, a difference that may influence the group comparison. Even though the nBNP group had normal NT-proBNP levels, these patients cannot be considered to represent a "healthy population", despite having normal hemodynamics. We did not have detailed echocardiographic results for these patients prior to the RHC. Patients were only encouraged to perform submaximal exercise and most did not develop severe symptoms. The cutoff for abnormality values from NT-proBNP ( $>125 \mathrm{ng} / \mathrm{l}$ ), PCWP $(>15 / 25 \mathrm{mmHg})$ and $\mathrm{mPAP}(>25 / 30 \mathrm{mmHg})$ at rest and exercise can be argued. However, we relied mainly on the recommendations published $[18,32]$.

\section{Conclusion}

The addition of PLL during RHC unmasked disturbed LV physiology and raised filling pressures in most patients presenting with eBNP. PLL had a sensitivity of $91 \%$ and specificity $92 \%$ for identifying significantly raised PCWP with exercise, which is the likely cause of unexplained dyspnea in these patients. Therefore, the use of PLL and exercise could be proposed as complimentary test for HF patients. Finally, using changes in mPAP/CO during exercise could also be proposed as a useful method for detecting abnormal filling pressures with stress.

Acknowledgements Open access funding provided by Umea University.

Funding Support from Heart and Lung foundation, Sweden.

\section{Compliance with ethical standards}

\section{Conflict of interest None.}

Open Access This article is distributed under the terms of the Creative Commons Attribution 4.0 International License (http://creativeco mmons.org/licenses/by/4.0/), which permits unrestricted use, distribution, and reproduction in any medium, provided you give appropriate credit to the original author(s) and the source, provide a link to the Creative Commons license, and indicate if changes were made.

\section{References:s}

1. Lavie CJ, Shah SB, Mehra MR (2018) The dilemma of exertional dyspnea and diagnosis of heart failure: convergent and discriminant validity. JACC Cardiovasc Imaging. https://doi.org/10.1016/j. jcmg.2017.09.014

2. Pozzoli M, Traversi E, Roelandt JR (2002) Non-invasive estimation of left ventricular filling pressures by Doppler echocardiography. Eur J Echocardiogr 3(1):75-79

3. Temporelli PL, Scapellato F, Eleuteri E, Imparato A, Giannuzzi P (2010) Doppler echocardiography in advanced systolic heart failure: a noninvasive alternative to Swan-Ganz catheter. Circ Heart Fail 3(3):387-394. https://doi.org/10.1161/CIRCHEARTF AILURE.108.809590

4. Popovic ZB, Sato K, Desai MY (2018) Is universal grading of diastolic function by echocardiography feasible? Cardiovasc Diagn Ther 8(1):18-28. https://doi.org/10.21037/cdt.2017.07.02

5. Nagueh SF, Smiseth OA, Appleton CP, Byrd BF, Dokainish H, Edvardsen T, Flachskampf FA, Gillebert TC, Klein AL, Lancellotti P, Marino P, Oh JK, Popescu BA, Waggoner AD (2016) Recommendations for the evaluation of left ventricular diastolic function by echocardiography: an update from the american society of echocardiography and the european association of cardiovascular imaging. J Am Soc Echocardiogr 29(4):277-314. https ://doi.org/10.1016/j.echo.2016.01.011

6. Grant AD, Negishi K, Negishi T, Collier P, Kapadia SR, Thomas JD, Marwick TH, Griffin BP, Popovic ZB (2015) Grading diastolic function by echocardiography: hemodynamic validation of existing guidelines. Cardiovasc Ultrasound 13:28. https://doi. org/10.1186/s12947-015-0023-6

7. Prasad SB, Holland DJ, Atherton JJ (2018) Diastolic stress echocardiography: from basic principles to clinical applications. Heart 104(21):1739-1748. https://doi.org/10.1136/heartjnl-2017-31232

8. Choi S, Shin JH, Park WC, Kim SG, Shin J, Lim YH, Lee Y (2016) Two distinct responses of left ventricular end-diastolic pressure to leg-raise exercise in euvolemic patients with exertional dyspnea. Korean Circ J 46(3):350-364. https://doi.org/10.4070/ kcj.2016.46.3.350

9. Matsuzoe H, Matsumoto K, Tanaka H, Hatani Y, Hatazawa K, Shimoura H, Ooka J, Sano H, Ryo-Koriyama K, Shinke T, Yamada H, Okita Y, Hirata KI (2017) Significant prognostic value of acute preload stress echocardiography using leg-positive pressure maneuver for patients with symptomatic severe aortic stenosis awaiting aortic valve intervention. Circ J 81(12):1927-1935. https ://doi.org/10.1253/circj.CJ-17-0143

10. Choi EY, Shim CY, Kim SA, Rhee SJ, Choi D, Rim SJ, Jang Y, Chung N, Cho SY, Ha JW (2010) Passive leg-raise is helpful to identify impaired diastolic functional reserve during exercise in patients with abnormal myocardial relaxation. J Am Soc Echocardiogr 23(5):523-530. https://doi.org/10.1016/j.echo.2010.02.004

11. Obokata M, Negishi K, Kurosawa K, Arima H, Tateno R, Ui G, Tange S, Arai M, Kurabayashi M (2013) Incremental diagnostic value of la strain with leg lifts in heart failure with preserved ejection fraction. JACC Cardiovasc Imaging 6(7):749-758. https ://doi.org/10.1016/j.jcmg.2013.04.006

12. Batson GA, Chandrasekhar KP, Payas Y, Rickards DF (1972) Measurement of pulmonary wedge pressure by the flow directed Swan-Ganz catheter. Cardiovasc Res 6(6):748-752

13. Galie N, Humbert M, Vachiery JL, Gibbs S, Lang I, Torbicki A, Simonneau G, Peacock A, Vonk Noordegraaf A, Beghetti M, Ghofrani A, Gomez Sanchez MA, Hansmann G, Klepetko W, Lancellotti P, Matucci M, McDonagh T, Pierard LA, Trindade PT, Zompatori M, Hoeper M (2016) 2015 ESC/ERS Guidelines for the diagnosis and treatment of pulmonary hypertension. Rev Esp Cardiol (Engl Ed) 69(2):177. https://doi.org/10.1016/j. rec.2016.01.002

14. Waxman $A B$ (2012) Exercise physiology and pulmonary arterial hypertension. Prog Cardiovasc Dis 55(2):172-179. https://doi. org/10.1016/j.pcad.2012.07.003

15. Borlaug BA, Nishimura RA, Sorajja P, Lam CS, Redfield MM (2010) Exercise hemodynamics enhance diagnosis of early heart failure with preserved ejection fraction. Circ Heart Fail 3(5):588595. https://doi.org/10.1161/CIRCHEARTFAILURE.109.930701

16. Penicka M, Bartunek J, Trakalova H, Hrabakova H, Maruskova M, Karasek J, Kocka V (2010) Heart failure with preserved ejection fraction in outpatients with unexplained dyspnea: a 
pressure-volume loop analysis. J Am Coll Cardiol 55(16):17011710. https://doi.org/10.1016/j.jacc.2009.11.076

17. Huis In't Veld AE, de Man FS, van Rossum AC, Handoko ML (2016) How to diagnose heart failure with preserved ejection fraction: the value of invasive stress testing. Neth Heart J 24(4):244 251. https://doi.org/10.1007/s12471-016-0811-0

18. Galie N, Humbert M, Vachiery JL, Gibbs S, Lang I, Torbicki A, Simonneau G, Peacock A, Vonk Noordegraaf A, Beghetti M, Ghofrani A, Gomez Sanchez MA, Hansmann G, Klepetko W, Lancellotti P, Matucci M, McDonagh T, Pierard LA, Trindade PT, Zompatori M, Hoeper M, Group ESCSD (2016) 2015 ESC/ERS Guidelines for the diagnosis and treatment of pulmonary hypertension: The Joint Task Force for the Diagnosis and Treatment of Pulmonary Hypertension of the European Society of Cardiology (ESC) and the European Respiratory Society (ERS): Endorsed by: Association for European Paediatric and Congenital Cardiology (AEPC), International Society for Heart and Lung Transplantation (ISHLT). Eur Heart J 37(1):67-119. https://doi.org/10.1093/eurhe artj/ehv317

19. Wolsk E, Bakkestrom R, Thomsen JH, Balling L, Andersen MJ, Dahl JS, Hassager C, Moller JE, Gustafsson F (2017) The influence of age on hemodynamic parameters during rest and exercise in healthy individuals. JACC Heart Fail 5(5):337-346. https://doi. org/10.1016/j.jchf.2016.10.012

20. Borlaug BA (2014) Mechanisms of exercise intolerance in heart failure with preserved ejection fraction. Circ J 78(1):20-32

21. Rosenkranz S, Gibbs JS, Wachter R, De Marco T, Vonk-Noordegraaf A, Vachiery JL (2016) Left ventricular heart failure and pulmonary hypertension. Eur Heart J 37(12):942-954. https://doi. org/10.1093/eurheartj/ehv512

22. Opdahl A, Remme EW, Helle-Valle T, Edvardsen T, Smiseth OA (2012) Myocardial relaxation, restoring forces, and early-diastolic load are independent determinants of left ventricular untwisting rate. Circulation 126(12):1441-1451. https://doi.org/10.1161/ CIRCULATIONAHA.111.080861

23. Ishizu T, Seo Y, Kawano S, Watanabe S, Ishimitsu T, Aonuma K (2008) Stratification of impaired relaxation filling patterns by passive leg lifting in patients with preserved left ventricular ejection fraction. Eur J Heart Fail 10(11):1094-1101. https://doi. org/10.1016/j.ejheart.2008.07.011

24. Eisman AS, Shah RV, Dhakal BP, Pappagianopoulos PP, Wooster L, Bailey C, Cunningham TF, Hardin KM, Baggish AL, Ho JE, Malhotra R, Lewis GD (2018) Pulmonary capillary wedge pressure patterns during exercise predict exercise capacity and incident heart failure. Circ Heart Fail 11(5):e004750. https://doi. org/10.1161/CIRCHEARTFAILURE.117.004750

25. Naeije R, Vanderpool R, Dhakal BP, Saggar R, Saggar R, Vachiery JL, Lewis GD (2013) Exercise-induced pulmonary hypertension: physiological basis and methodological concerns. Am J Respir Crit Care Med 187(6):576-583. https://doi.org/10.1164/ rccm.201211-2090CI
26. Lewis GD, Bossone E, Naeije R, Grunig E, Saggar R, Lancellotti P, Ghio S, Varga J, Rajagopalan S, Oudiz R, Rubenfire M (2013) Pulmonary vascular hemodynamic response to exercise in cardiopulmonary diseases. Circulation 128(13):1470-1479. https://doi. org/10.1161/CIRCULATIONAHA.112.000667

27. Herve P, Lau EM, Sitbon O, Savale L, Montani D, Godinas L, Lador F, Jais X, Parent F, Gunther S, Humbert M, Simonneau G, Chemla D (2015) Criteria for diagnosis of exercise pulmonary hypertension. Eur Respir J 46(3):728-737. https://doi. org/10.1183/09031936.00021915

28. Sharifov OF, Schiros CG, Aban I, Denney TS, Gupta H (2016) Diagnostic accuracy of tissue doppler index e/e' for evaluating left ventricular filling pressure and diastolic dysfunction/heart failure with preserved ejection fraction: a systematic review and meta-analysis. J Am Heart Assoc. https://doi.org/10.1161/ JAHA.115.002530

29. Nauta JF, Hummel YM, van der Meer P, Lam CSP, Voors AA, van Melle JP (2018) Correlation with invasive left ventricular filling pressures and prognostic relevance of the echocardiographic diastolic parameters used in the 2016 ESC heart failure guidelines and in the 2016 ASE/EACVI recommendations: a systematic review in patients with heart failure with preserved ejection fraction. Eur J Heart Fail 20(9):1303-1311. https://doi.org/10.1002/ejhf.1220

30. Nagueh SF, Smiseth OA, Appleton CP, Byrd BF, Dokainish H, Edvardsen T, Flachskampf FA, Gillebert TC, Klein AL, Lancellotti P, Marino P, Oh JK, Alexandru Popescu B, Waggoner AD, Houston T, Oslo N, Phoenix A, Nashville T, Hamilton OC, Uppsala S, Ghent LB, Cleveland O, Novara I, Rochester M, Bucharest $\mathrm{R}$ (2016) Recommendations for the evaluation of left ventricular diastolic function by echocardiography: an update from the american society of echocardiography and the european association of cardiovascular imaging. Eur Heart J Cardiovasc Imaging 17(12):1321-1360. https://doi.org/10.1093/ehjci/jew082

31. Andersen OS, Smiseth OA, Dokainish H, Ha JW, Klein AL, Nagueh SF (2017) Reply: issues with estimating "diastolic function" and left ventricular filling pressure using the new guidelines. J Am Coll Cardiol 70(9):1198-1199. https://doi.org/10.1016/j. jacc.2017.05.073

32. Ponikowski P, Voors AA, Anker SD, Bueno H, Cleland JGF, Coats AJS, Falk V, Gonzalez-Juanatey JR, Harjola VP, Jankowska EA, Jessup M, Linde C, Nihoyannopoulos P, Parissis JT, Pieske B, Riley JP, Rosano GMC, Ruilope LM, Ruschitzka F, Rutten FH, van der Meer P, Group ESCSD (2016) 2016 ESC Guidelines for the diagnosis and treatment of acute and chronic heart failure: the task force for the diagnosis and treatment of acute and chronic heart failure of the European Society of Cardiology (ESC)Developed with the special contribution of the Heart Failure Association (HFA) of the ESC. Eur Heart J 37(27):2129-2200. https:// doi.org/10.1093/eurheartj/ehw128 